\title{
Laparoscopic management of liver echinococcal cyst at B.P.Koirala Institute of Health Sciences Dharan, Nepal an institutional review
}

\author{
S Sah ${ }^{1}$, S Adhikary ${ }^{1}$, CS Agrawal ${ }^{1}$, R Gupta ${ }^{1}$, A Ghimire ${ }^{2}$ \\ Department of Surgery ${ }^{1}$, Department of Anesthesia ${ }^{2}$ \\ B.P. Koirala Institute of Health Sciences, Dharan, Nepal
}

\begin{abstract}
Background: Hydatid disease is an endemic disease in several parts of the world. Surgeons and physicians in the non-endemic areas may encounter the disease. Surgery remains the mainstay of therapy. Recently, laparoscopic treatment of hepatic hydatid disease has been increasingly popular and has undergone a revolutionary parallel to the progress in laparoscopic surgery. It is a new and encouraging approach with minimum morbidity and mortality. Objective: To assess the outcome of laparoscopic management of hydatid cyst. Methods: A retrospective \& prospective case series study included all patients of hydatid liver cysts who were managed laparoscopically from $1^{\text {st }}$ January 2008- $31^{\text {st }}$ June 2013 (five \& half yrs). Patients with deep intraparenchymal location of the cyst, more than 3 cysts and cysts with calcified walls were excluded. Results: Thirty two patients were included in this study to know the results of the laparoscopic management of hepatic hydatid cyst disease. Majority of patients in the age

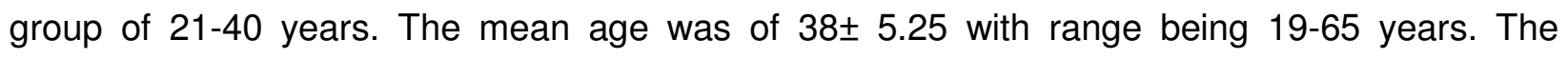
commonest presentation of dull aching pain in right upper quadrant was seen in $21(62.5 \%)$ patients followed by hepatomegaly in $12(37.5 \%)$ patients \& right upper abdominal lump in 8 $(25 \%)$ patients. Twenty seven (84.3\%) patients had single cyst \& 5 (15.6\%) patients had two cysts. The mean diameter of the cyst was $9.2 \pm 2.72 \mathrm{~cm}$ in size. The mean operative time was (65.42 $\pm 12.67 \mathrm{~min})$ with range being $45-125$ mins. Conclusion: The laparoscopic approach is safe \& feasible in selected patients. The treatment choices of hydatid disease of the liver have increased in the last 2 decades including medical treatment, percutaneous drainage, or a combination.
\end{abstract}

Keywords: Echinococcus, laparoscopy, liver cyst

\author{
Address for correspondence \\ Dr. Suresh Prasad Sah \\ Assistant Professor \\ Department of Surgery \\ B.P. Koirala Institute of Health Sciences, Dharan \\ E-mail: Sureshsah214@gmail.com
}




\section{Introduction}

Hydatid disease is an endemic disease in several parts of the world. Surgeons and physicians in the non-endemic areas may encounter the disease sporadically owing to increased travel and immigration. ${ }^{1,}{ }^{2}$ Hydatid disease has been known to mankind since ancient times. Hippocrates described it as 'liver full of water.' The disease is caused by Echinococcus granulosus, a cestode that lives in the small intestine of dogs and other canines. Eggs eliminated in their feces are ingested by intermediate hosts i.e. sheep, goats or reindeer. Humans are accidental intermediate hosts. The larvae are liberated in the duodenum, cross the intestinal wall and reach the hepatic sinusoids via portal system, and forms hydatid cyst in liver. ${ }^{1,}{ }^{3}$ Hydatid cysts commonly occur in the liver $(50 \%$ to $93 \%$ ). If left untreated, the cysts grow and may lead to fistula formation into adjacent organs or the biliary system, or ruptures into the peritoneal cavity causing seeding of multiple daughter cysts throughout peritoneal cavity. ${ }^{1,2}$ The treatment choices of hydatid disease of the liver have increased in the last 2 decades including medical treatment, PAIR technique, percutaneous drainage, or a combination. Surgery remains the mainstay of therapy. However, fear of anaphylactic shock resulting from spillage of hydatid fluid during treatment by the minimally invasive method may discourage a wider adoption of this technique. ${ }^{4,5,6}$ Recently, laparoscopic treatment of hepatic hydatid disease has been increasingly popular and has undergone a revolutionary parallel to the progress in laparoscopic surgery. ${ }^{7}$ The aim of this study was to assess the outcome of laparoscopic treatment of hepatic hydatid disease.

\section{Methods}

The study was conducted in B.P. Koirala Institute of Health Sciences, Dharan, Nepal from $1^{\text {st }}$ January $2008-31^{\text {st }}$ June 2013 (five \& half yrs). A retrospective \& prospective case series study included all patients of hydatid liver cysts who were managed laparoscopically. Patients with deep intraparenchymal location of the cyst, more than 3 cysts and cysts with calcified walls were excluded in the analysis.

Each patient's medical record was reviewed. All the clinical features, physical examination findings, serological tests, abdominal ultrasound (US), abdominal computed tomography (CT) scan reports, operative time, conversion to laparotomy, morbidity, mortality and recurrences were recorded in predesigned performa. The Gharbi classification system was used to stage the 
hydatid disease. All patients were treated with albendazole $(10 \mathrm{mg} / \mathrm{kg}) 2$ wks prior to surgery and continued postoperatively for 8 weeks. All procedures were done under general anesthesia. Antibiotic (Ceftriaxone 1gm) administered with the induction of anesthesia. A $30^{\circ}$ degree telescope was inserted via an infraumbilical port after creating pneumoperitoneum, and the cyst identified on the surface of the liver. Another port was inserted from a point close to the cyst, on the right side and an aspiration needle introduced into the peritoneal cavity. A third port inserted for mobilization and access. To prevent accidental spillage of the cystic contents, the puncture site was covered with betadine soaked gauzes. The cyst fluid was aspirated, $10 \%$ betadine solution (scolicidal agent) was injected into the cyst cavity and aspirated after 10 minutes, followed by unroofing of the cyst wall. A sucker was introduced and all the cyst contents were thoroughly evacuated and irrigated with betadine solution. The cavity was examined for any remaining contents, daughter cysts and biliary leak. The remaining cystic cavity was obliterated by omentum. A drainage tube was introduced into the cyst cavity for postoperative drainage. Laparoscopic surgery (partial pericystectomy + omentopexy) was done. Visual analogue scale used for pain assessment before \& after operation. All the datas were entered in icrosoft excel chart \& analysis was done by using SPSS15 version. Descriptive analysis was done in the form of mean, median, mode \& standard deviation. Frequency tables were used for descriptive analysis.

\section{Results}

Thirty-two patients were included in this study to assess the outcome of the laparoscopic management of hepatic hydatid cyst disease in terms of symptom relieve, complications, conversion \& recurrence rate. Out of 32 patients, 19 were females \& 13 were males with $\mathrm{F}: \mathrm{M}$ ratio of $1.46: 1$.

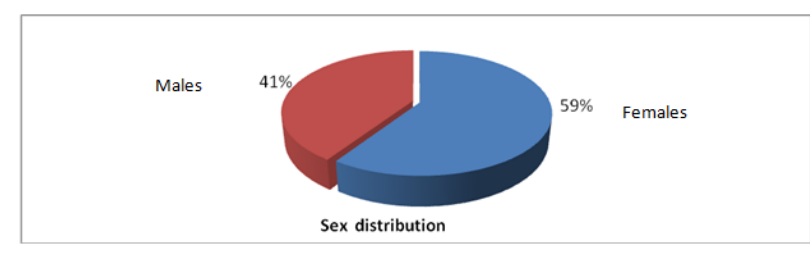

Fig. 1 : Sex distribution

Majority of patients were in the age group of 21-40 yrs. The mean age was of $38 \pm 5.25$ with range being 19-65 yrs.

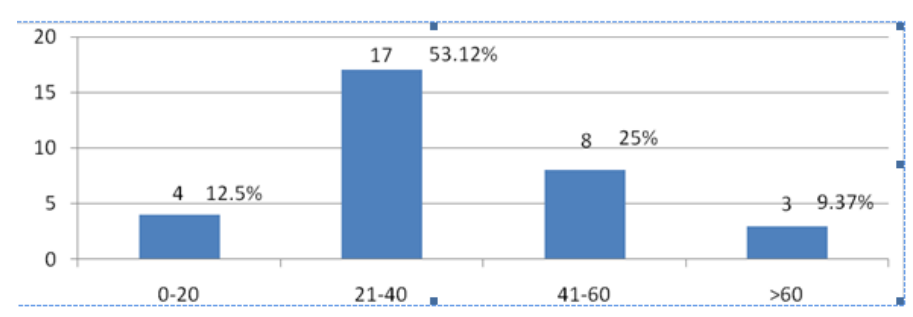

Fig. 2: Age distribution 
Majority of patients were housewife by occupation followed by farmers \& others. History of contact with pets was seen in 7 patients.

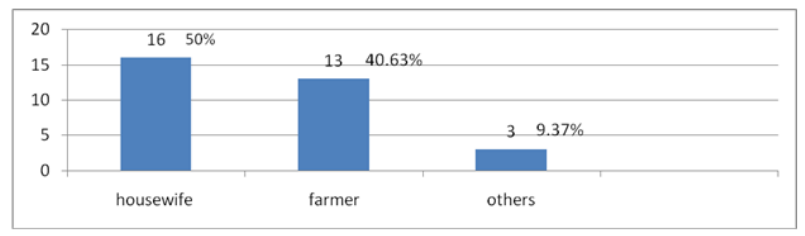

Fig. 3: Occupation

The commonest presentation of dull aching pain in right upper quadrant was seen in $21(62.5 \%)$ patients followed by hepatomegaly in $12(37.5 \%)$ patients \& right upper abdominal lump in $8(25 \%)$ patients. Echinococcal cyst was found in 10 (31.25\%) asymptomatic patients on screening ultrasound for other reasons.

\section{Table 1}

\begin{tabular}{|l|l|l|}
\hline Symptoms/sign & Number of patients & percentage \\
\hline $\begin{array}{l}\text { Dull aching pain in right upper } \\
\text { quadrant }\end{array}$ & 21 & $62.5 \%$ \\
\hline Hepatomegaly & 12 & $37.5 \%$ \\
\hline Right upper abdominal lump & 8 & $25 \%$ \\
\hline
\end{tabular}

Ultrasonography was done in every patient. Computerized tomography scan was done in 9 cases where results of ultrasonography were equivocal \& to know the exact anatomical site and number of intrahepatic cysts. Chest radiographs showed an elevated right hemi-diaphragm in 7 patients.

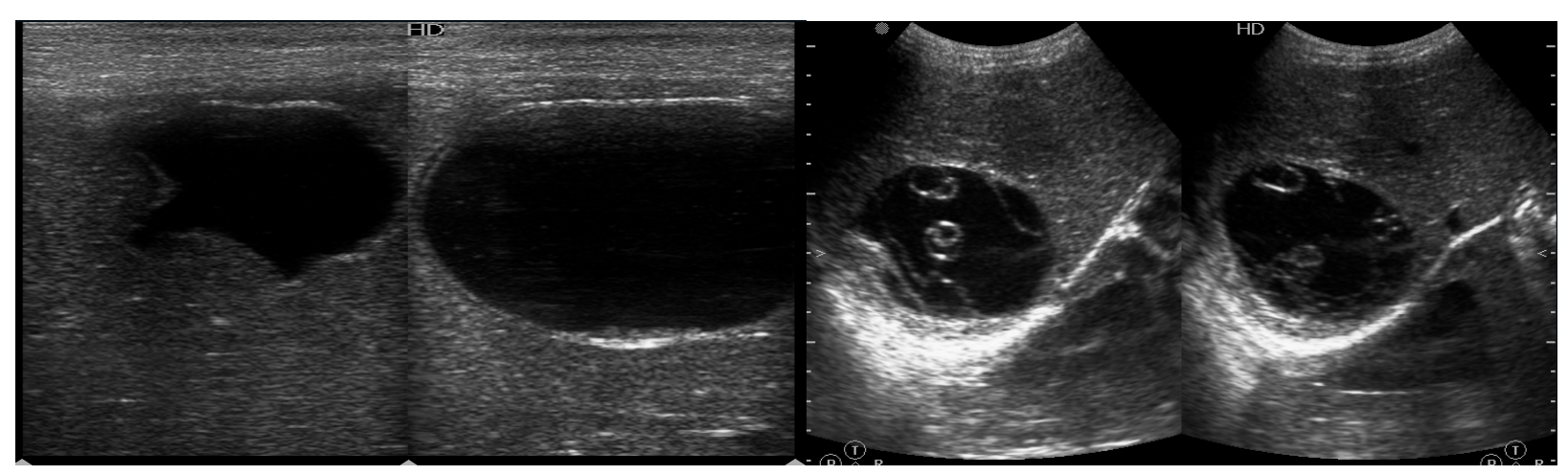

Fig. 4: Ultrasonographs showing hydatid cyst with laminated membrane \& daughter cysts 
Table 2: Number \& location of cyst

\begin{tabular}{|l|l|l|}
\hline & Number of patients & Percentage \\
\hline Number of cyst & & \\
\hline Single cyst & 27 & $\mathbf{8 4 . 3 7 \%}$ \\
\hline 2 cysts & 5 & $15.62 \%$ \\
\hline Location & & \\
\hline Right lobe & 26 & $\mathbf{8 1 . 2 5} \%$ \\
\hline Left lobe & 4 & $12.5 \%$ \\
\hline Both lobes & 2 & $6.25 \%$ \\
\hline
\end{tabular}

The mean diameter of the cyst was $9.2 \pm 2.72$ $\mathrm{cm}$ in size. Three patients had jaundice out of which two had features of obstructive jaundice on liver function tests. Two patients

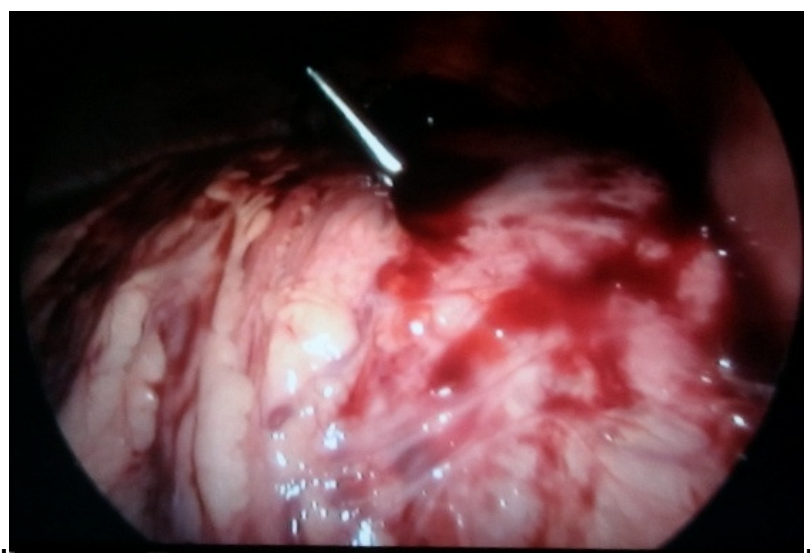

each had associated lung hydatid disease \& gallstone disease. The mean operative time was $65.42 \pm 12.67 \mathrm{~min}$ with range being $45-125$ $\min$.

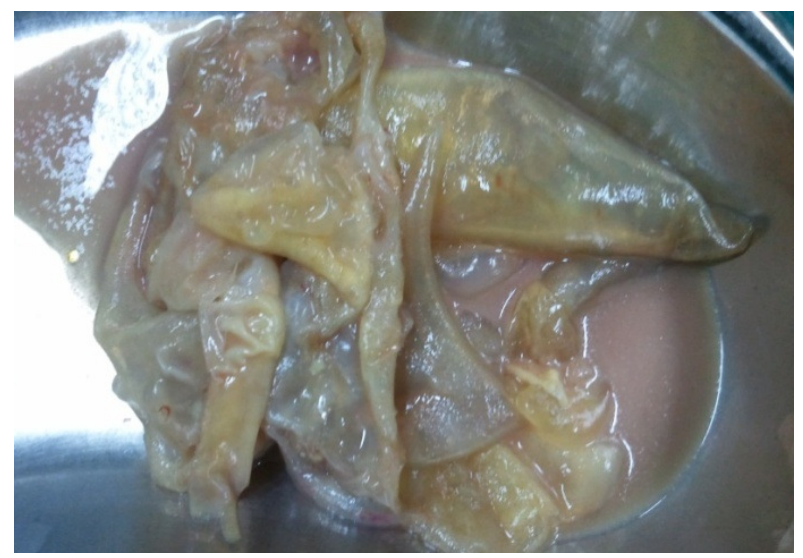

Fig. 5: Laparoscopic view of hydatid cyst of liver containing laminated membrane with few daughter cysts

Visual analogue scale (VAS) was used to assess pain at the time of admission and at the time of discharge. Mean VAS at the time of admission was $5.7 \pm 1.2$ and mean VAS at the time of discharge was $2.1 \pm 1.3$. Lump \& hepatomegaly subsided in all those patients who had presented with it. 
Table 3: Complications of surgery

\begin{tabular}{|l|l|l|}
\hline Complications & Number of patients & Percentage \\
\hline Anaphylactic shock & 2 & $6.25 \%$ \\
\hline Port site infection & 3 & $9.37 \%$ \\
\hline Bile leakage & 2 & $6.25 \%$ \\
\hline Conversion & 4 & $12.50 \%$ \\
\hline Recurrence & 1 & $3.12 \%$ \\
\hline
\end{tabular}

Two patient developed anaphylaxis during immediate postoperative period but were managed successfully. Two patients had bile leak \& mild peritonitis managed conservatively with antibiotics \& keeping the suction drain for longer duration. In 4 patients $(12.5 \%)$, procedure was converted to open surgery because of inadequate exposure and access. One patient (3.12\%) had recurrence after six month.

A majority of the patients belonged to remote area so a follow-up remained poor. There was no mortality in the series. The mean hospital stay was $4.5 \pm 1.2$ days \& return to work was within 8-10 days.

\section{Discussion}

Palnivelu et al. reported that hydatid cyst disease of the liver is widespread in India \& Asian countries. The commonly affected age group is the third and fourth decade. In non- endemic areas, it can affect all age groups. Both sexes are affected by this disease, but it is more common in females, the female-tomale ratio is $1.77: 1 .{ }^{2,3}$ In our review also females are more commonly affected than males with F: M ratio (1.46:1). In 2006, Bickel et al reported ten cases of hepatic hydatid cyst treated laparoscopically without mortality or relapse. ${ }^{4}$

Complications included, port site infection, biliary leakage and peritonitis, which were managed conservatively. Late complications included hernia and recurrence in $4.65 \%$ each. In another series, infection was reported in 2 (3\%), biliary leakage in 9 $(13.7 \%)$ cases, which responded to conservative management. Others have reported $4 \%$ perioperative, $17 \%$ postoperative complications with recurrence in 1 (9\%) cases. $^{2,6}$ In our review 2 (6.25\%) patients developed anaphylaxis during 
immediate postoperative period and were managed successfully. Three patients (9.37\%) had port site infection \& $2(6.25 \%)$ patients had bile leak managed conservatively.

Ertem et al. has reported successful laparoscopic partial pericystectomy with drainage in 33 patients along with omentopexy in 15 patients with conversion to open surgery in only 2 patients. ${ }^{5}$ In our review 4 patients (12.5\%), procedure was converted to open surgery because of inadequate exposure and access. The recurrence rate ranges from $3 \%$ to $10 \%$ following open surgery for hepatic hydatid cysts. ${ }^{7}$ In our study one (3.12\%) patient had recurrence.

Haddad et al. reported that about $64.4 \%$ present with abdominal pain; in $77 \%$ of cases, the cyst is in the right lobe; in $93.4 \%$ of cases, it is superficial. ${ }^{8}$ In our series $62.5 \%$ patients had dull aching right upper abdominal pain, $84.37 \%$ patient had single cyst \& in $81.25 \%$ cyst was located in right lobe.

Gharbi et al. has reported in their report that most of the cysts are without any complication - a few are complicated by a rupture, intraperitoneal $(3.2 \%)$ or intrabiliary $(8.2 \%) .{ }^{9}$ Saglam et al. proposed the laparoscopic technique as a method for treating hepatic hydatid cyst. ${ }^{10} \mathrm{~A}$ major disadvantage of laparoscopy is the lack of precautionary measures concerning spillage. Various instruments have been described to evacuate the contents of the cyst without spillage. ${ }^{11,} 12$ Various laparoscopic techniques described are total pericystectomy, puncture and aspiration of contents followed by marsupialization, unroofing and drainage, unroofing and omentoplasty. ${ }^{13,14}$ According to Palanivelu et.al hydatid system not only prevents spillage, but also assists complete evacuation and allows intracystic magnified visualization for cyst-biliary communication. ${ }^{2}$ These specialized devices are not available at our study centre.

\section{Conclusion}

The laparoscopic approach is safe \& feasible in selected patients. The treatment choices of hydatid disease of the liver have increased in the last 2 decades including medical treatment, percutaneous drainage, or a combination. However, Surgery remains the mainstay of therapy. It is a new and encouraging approach with minimum morbidity and mortality. It is a simple technique with potentially decreased risk of intra-abdominal spillage, lesser complications and recurrence. It also offers all the advantages of minimally invasive surgery. However, further studies are needed in this field because there is no universally accepted standard technique. 


\section{References}

1. Huizinga WK, Grant CS, Daar AS. Hydatid disease. In: Morris PJ, Wood WC, editors. Oxford textbook of surgery. 2nd ed. New York: Oxford University Press; 2000. p. 3298-305

2. Palnivelu C, Jani K, Malladi V, Senthilkumar R, Rajan PS, Sendhilkumar K, et al. Laparoscopic management of hepatic hydatid disease. JSLS 2006; 10:56-62.

3. King $\mathrm{CH}$. Cestodes (tapeworms). In: Mandell GL, Bennett JE, Dolin R, editors. Principles and practice of infectious diseases. 4th ed. New York: Churchill Livingstone; 1995. p. 2544-53.

4. Bickel A, Daud G, Urbach D, Lefler E, Barasch EF, Eitan A.Laparoscopic approach to hydatid liver cysts. Is it logical? Physical, experimental, and practical aspects. Surg Endosc 1998; 12:1073-7.

5. Ertern M, Uras C, Karahasanoglu T, Erguney S, Alemdaroglu $\mathrm{K}$. Laparoscopic approach to hepatic hydatid disease. Dig Surg 1998; 8:2802.

6. Yaghan $\mathrm{R}$, Heis $\mathrm{H}$, Bani-Hani $\mathrm{K}$, Matalka I, Shatanawi N,Gharaibeh K, Bani-Hani A. Is fear of anaphylactic shock discouraging surgeons from more widely adopting percutaneous and laparoscopic techniques in the treatment of liver hydatid cyst? Am J Surg 2004; 187:533-7.

7. Ertem M, Karahasanoglu T, Yavuz N, Erguney S. Laparoscopically treated liver hydatid cysts. Arch Surg. 2002; 137:1170-3.

8. Haddad MC, Al-Awar G, Huwaijah $\mathrm{SH}$, Al-Kutoubi AO. Echinococcal cysts of the liver: a retrospective analysis of clinico-radiological findings and different therapeutic modalities. Clin Imaging 2001; 25:403-408.

9. Gharbi HA, Hassine W, Brauner MW, Dupuch K. Ultrasound examination of the hydatic liver. Radiology 1981; 139:459-463.

10. Saglam A. Laparoscopic treatment of liver hydatid cysts. Surg Laparosc Endosc 1996; 6: 16-21.

11. Alper A, Emre A, Acarli K, Bilge $O$, Ozden I, Ariogul O.Laparoscopic treatment of hepatic hydatid disease. $\mathrm{J}$ Laparoendosc Surg 1996; 6: 29-33

12. Misra MC, Khan RN, Bansal VK, Jindal $\mathrm{V}$, Kumar S, Noba AL, et al. Laparoscopic pericystectomy for hydatid cyst of the liver. Surg Laparosc Endosc Percutan Tech 2010; 20:24-26.

13. Sharma D, Babu $R$, Borgharia $S$, Baruah D, Thomas S, Kumar A. Laparoscopy for liver hydatid disease: 
where do we stand today? Surg Laparosc Endosc Percutan Tech 2009; 19:419-423.

14. Goldin SB, Mateka JJ, Schnaus MJ, Dahal S. Laparoscopic drainage of a hepatic echinococcal cyst: a case report. Case Rep Gastrointest Med 2011; 2011:107087. 